\title{
United States proposes universal labelling standards for prescriptions
}

$\mathrm{W}$ ith studies indicating that almost half of American patients misunderstand dosing instructions on their prescriptions and more than a million "adverse drug events" are caused annually by misuse, authorities in the United States are moving to implement national labelling standards to reduce nonadherence and medication errors.

The standards, which would affect the content, language, format and appearance of all prescription medicine labels, were crafted by an expert panel appointed by the US Pharmacopeial Convention (USP).

The standards would help to "fulfill the professional obligations of the prescriber and pharmacist. These obligations include giving the patients the most essential information needed to understand how to safely and appropriately use the medication and to adhere to the prescribed medication regime," according to the USP Safe Medication Use Expert Committee (www.usp.org/pdf/EN/US PNF/M5531.pdf).

Proponents hope the standards would also substantially reduce medication mishaps. According to a US Institute of Medicine study, Preventing Medication Errors, unintended misuse of prescription drugs causes on the order of one million adverse drug events annually in the US, which has costly consequences, including death, as well as increased visits to emergency rooms and increased hospitalization rates (http://books.nap .edu/openbook.php?record_id=11623).

The proposed standards would significantly alter labelling on prescription containers so that information is presented in a "patient-centred manner." Among the proposed changes:

- More prominent display of information 'that is critical for patients' safe and effective use of the medicine. Place at the top of the label the patient's name, drug name and strength, and explicit clear directions

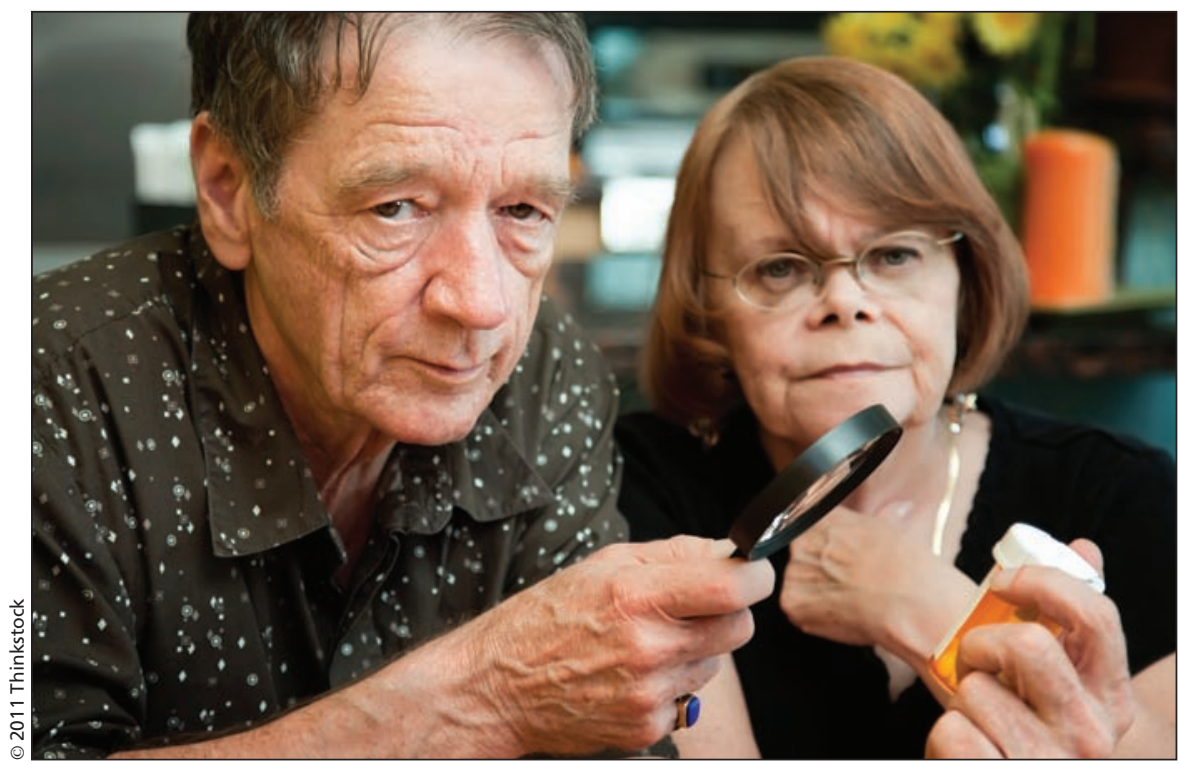

Among recommended changes on prescription labels is one to improve readability by using clear fonts and colours.

for use in simple language." Less critical information - such as the pharmacy's name, phone number, the prescriber's name, refill information, etc. - would be placed at the bottom of labels, where it would not "distract" patients, or "impair their recognition and understanding."

- Use language that is "clear, simplified, concise and familiar," in a standardized fashion, rather than "unfamiliar words (including Latin terms) or unclarified medical jargon."

- Give explicit instructions on the dosing regimen "in order to explicitly convey the number of dosage units to be taken and when (e.g., specific time periods each day such as morning and evening or at breakfast and dinner). Instructions should use numeric rather than alphabetic characters for numbers (e.g., write, 'Take 2 tablets in the morning and 2 tablets in the evening' rather than 'Take two tablets twice daily').

- Include information about the purpose for use of the medication, in simple terms. For example: for "high blood pressure," rather than for "hypertension." (The panel acknowledged that this would be problematic for off-label use of a drug).

- Present auxiliary information, such as "do not take with alcohol" in simple terms, rather than using icons.

- Provide prescription instructions in the preferred language of the patient.

- Improve readability by using clear fonts and colours.

Expert panel cochair Dr. Joanne Schwartzberg argues that improved labelling of prescriptions is necessary because they are a primary form of communication with patients. "The label is the best instruction material we have because it's always with the medicine," says Schwartzberg, director of aging and community health at the American Medical Association.

Schwartzberg cites the dosage regimen as a typical example of confusion surrounding labels. Some patients interpret "take two tablets twice daily" to mean that they should take two tablets a day instead of four, she notes. People often interpret "two" as being 
the number of times a day instead of doubling the dose, she says. "It's kind of inconceivable but it's such a common mistake."

The standards were developed in response to Institute of Medicine and consumer concerns, and are derived, in part, from the notion of a universal medicine schedule, which essentially proposed to use four explicit time intervals - breakfast, lunch, dinner and bedtime - as the basis for dosage regimens.

Dr. Ruth Parker, who helped develop the schedule, A Universal Medication Schedule to Promote Patient Understanding and Use, (www.ahrq.gov/about /annualconf09/wolf.htm), notes that the simple instruction "take one pill a day," can be written 44 different ways.

With regard to the somewhat problematic issue of ensuring that prescription instructions are properly translated, Schwartberg says a computer translation program would be ideal but in the interim, pharmacists working in areas with diverse populations should have access to a live translator who can work through the label with a patient.

In Canada, prescription container labels are not currently regulated by Health Canada, but fall under the jurisdiction of provincial governments and de facto, to pharmacy preferences.

But Health Canada writes in an email that they have examined the proposed US labelling standards and "discussions on next steps and recommendations stemming from this session are being considered."

Jurisdictional challenges also exist in the US, where each state has regulatory authority over its own pharmaceutical boards, making mandatory national standards impossible.

But two states have already moved forward in an effort to standardize labels, in a fashion consistent with the proposed national standards, says Shawn Becker, director of healthcare quality standards for the US Pharmacopeial Convention. California's regulations came into effect in January (www.pharmacy.ca.gov/laws_regs/new _laws.pdf), while New York has introduced legislation (http://open.nysenate .gov/legislation/bill/S5000-2011).

Becker, who argues that clarity is vital on labels, says the US Pharmacopeial Convention hopes to see the final version of the standards published by May 2012 but must still build a consensus behind the new standards. "We set the standards, but we don't enforce the standards. What we would want is the support from the boards of pharmacy or other regulatory agencies to pick these standards up and enforce them in their states." - Erin Walkinshaw, Ottawa, Ont.

CMAJ 2011. DOI:10.1503/cmaj.109-3908 